BMJ Open

Diabetes

Research

\& Care

\section{Iron parameters in patients with partial lipodystrophy and impact of exogenous leptin therapy}

Efe Y Akinci, ${ }^{1}$ Sabine Boutros, ${ }^{1}$ Benjamin J Ryan, ${ }^{2}$ Pinar Sargin,,${ }^{1}$ Baris Akinci, ${ }^{1}$ Adam H Neidert, ${ }^{1}$ Rita Hench, ${ }^{1}$ Jeffrey F Horowitz, ${ }^{2}$ Elif A Oral (ㄷ) ${ }^{1}$

To cite: Akinci EY, Boutros S, Ryan BJ, et al. Iron parameters in patients with partial lipodystrophy and impact of exogenous leptin therapy. BMJ Open Diab Res Care 2021;9:e002385. doi:10.1136/ bmjdrc-2021-002385

Received 14 May 2021 Accepted 19 June 2021
Check for updates

(C) Author(s) (or their employer(s)) 2021. Re-use permitted under CC BY-NC. No commercial re-use. See rights and permissions. Published by BMJ.

${ }^{1}$ Brehm Center for Diabetes Research and Division of Metabolism, Endocrinology and Diabetes, University of Michigan, Ann Arbor, Michigan, USA

${ }^{2}$ Substrate Metabolism Laboratory, School of Kinesiology, University of Michigan, Ann Arbor, Michigan, USA

Correspondence to Dr Elif A Oral; eliforal@umich.edu
Provocative rodent studies taken together with cross-sectional human epidemiological data have shown that there may be a cross-talk between circulating leptin levels and wholebody iron metabolism. ${ }^{12}$ In this study, we aim to discover the effects of recombinant leptin administration on iron parameters in patients with partial lipodystrophy.

We studied serum samples from 19 patients with partial lipodystrophy (median age: 42 years, IQR: 34-57, male/female: 3/16) gathered from an open-label study previously performed at the University of Michigan (ClinicalTrials.gov identifier: NCT01679197; article in press). All patients included in this analysis had familial partial lipodystrophy. We measured iron (assay range: $5-1000 \mu \mathrm{g} / \mathrm{dL}$ ), soluble transferrin receptor (sTfR; assay range: $3.0-80.0 \mathrm{nmol} / \mathrm{L}$ ), hepcidin (assay range: $2.5-1000 \mathrm{ng} / \mathrm{mL}$ ), and high-sensitive $\mathrm{C}$ reactive protein (hs-CRP; assay range $0.1-80 \mathrm{mg} / \mathrm{L}$ ) levels using commercially available assays. We integrated the results into an existing database of metabolic parameters. Repeated-measures analysis of variance was used to compare multiple time points. Paired t-test was used to compare month 6 values to baseline (a prespecified endpoint). Otherwise, multiplicity correction was performed. Normality was assessed by the Kolmogorov-Smirnov test and the Shapiro-Wilk's W test and also by plotting a histogram of the variable of interest. Log transformation was used for skewed data. Data are presented as median, IQR.

At baseline, ferritin levels were positively correlated with fasting glucose $(\mathrm{r}=0.533$; $\mathrm{p}=0.023$; figure $1 \mathrm{~A})$ and HbA1c $(\mathrm{r}=0.510$; $\mathrm{p}=0.031$; figure $1 \mathrm{~B})$. We also calculated Homeostatic Model Assessment for Insulin Resistance (HOMA-IR) in 14 participants who underwent a mix-meal test in the parent protocol for whom fasting insulin measurements were available. In these participants, HOMA-IR was correlated with serum iron levels $(\mathrm{r}=0.592 ; \mathrm{p}=0.030)$. After 6 months of therapy, hepatic fat content measured by MRI Dixon method decreased $(12.7 \%, 9.8-20.6$ vs $8.9 \%, 7.0-11.0 ; \mathrm{p}=0.031$ ). Triglyceride levels tended to decrease at 6 months $(346 \mathrm{mg} / \mathrm{dL}$, 240-1771 vs $295 \mathrm{mg} / \mathrm{dL}, 207-495 ; \mathrm{p}=0.091$ ). HbA1c levels did not change significantly $(9.2 \%, 7.3-10.3$ vs $8.5 \%, 6.8-9.5 ; \mathrm{p}=0.264)$.

We observed significant reductions in serum ferritin after treatment $(\mathrm{F}=6.436$, $\mathrm{p}=0.004 ; 83 \mathrm{ng} / \mathrm{mL}, 76-179$ vs month 3: $74 \mathrm{ng} / \mathrm{mL}, 68-79 ; \mathrm{p}=0.007$; and month 6 : $61 \mathrm{ng} / \mathrm{mL}, \quad 46-158 ; \mathrm{p}=0.004$; figure $1 \mathrm{C}$ ). Although slight reductions were observed in circulating levels of iron (figure 1D) and hepcidin (figure 1E), these changes did not reach statistical significance. Changes in sTfR were not statistically significant either. However, there were notable reductions in hs-CRP levels at 6 months $(2.9 \mathrm{mg} / \mathrm{L}, 1.3-4.8$ vs $1.6 \mathrm{mg} / \mathrm{L}, 1.0-6.3 ; \mathrm{p}=0.012$; figure $1 \mathrm{~F}$ ). Additionally, we observed modest correlations between changes in serum iron and triglycerides $(\mathrm{r}=0.491, \mathrm{p}=0.033)$ and hepatic fat $(\mathrm{r}=0.412, \mathrm{p}=0.079)$.

In the NHANES Study, higher serum ferritin levels were associated with newly diagnosed diabetes. ${ }^{3}$ Elevated levels of ferritin have been previously linked to altered fat distribution. ${ }^{4}$ Likewise, decreased iron stores as a result of phlebotomy have been associated with improved insulin sensitivity. ${ }^{5}$ In keeping with previous evidence from type 2 diabetes and metabolic syndrome, we found a significant relationship between ferritin and glycemic status in patients with partial lipodystrophy.

In an intriguing translational study, Gao et $a l^{1}$ reported that serum ferritin was one of the best predictors of serum leptin under physiological conditions. The study also reported that adipocyte-specific loss of the iron exporter ferroportin resulted in iron loading and decreased leptin. Although hepcidin and 

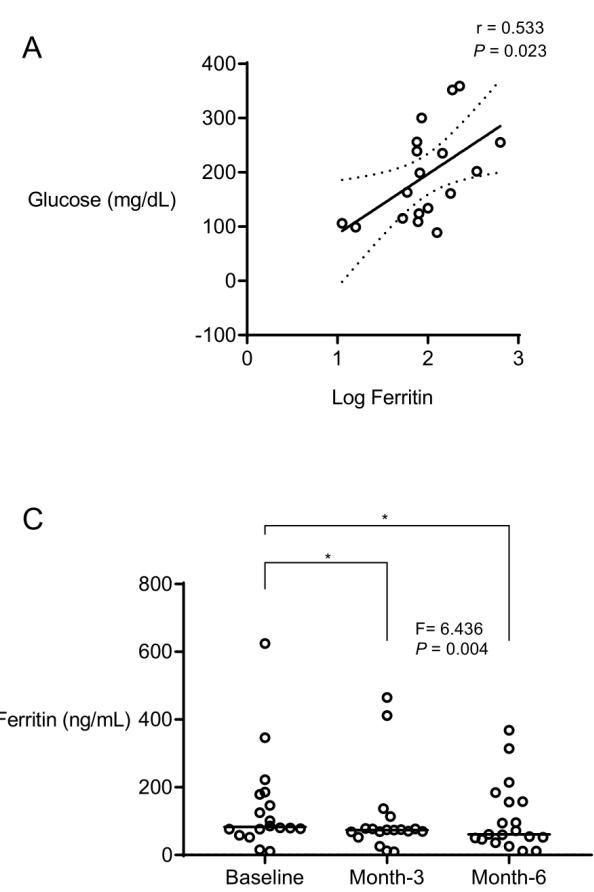

$\mathrm{E}$

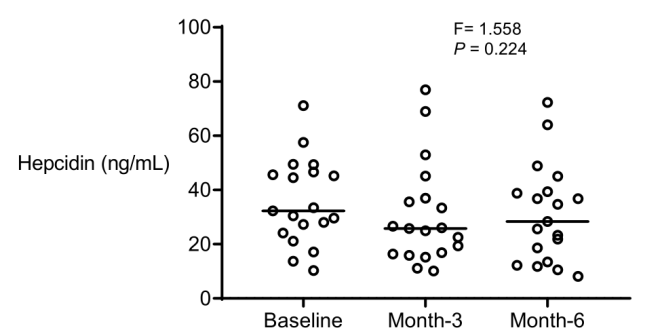

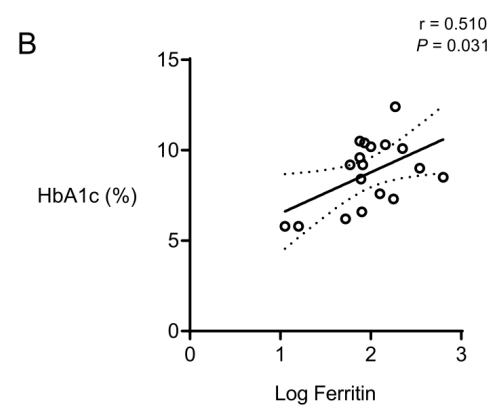

$\mathrm{D}$

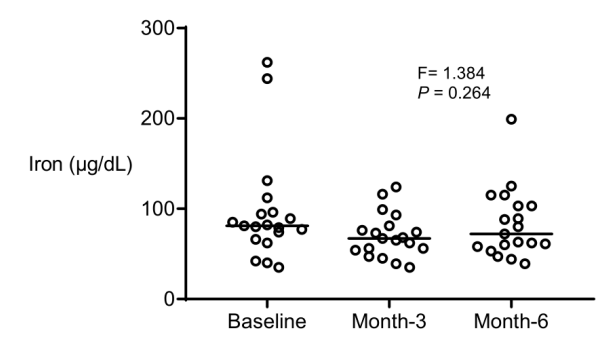

$\mathrm{F}$

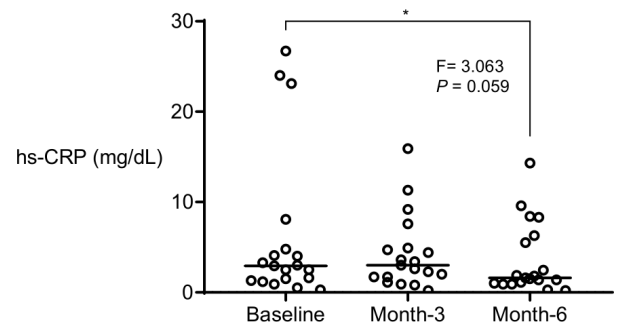

Figure 1 Correlation of ferritin with fasting glucose (A) and HbA1c (B). The effect of exogenous leptin on ferritin (C), iron (D), hepcidin (E) and hs-CRP (F). Data are presented as median, IQR. We report the F-statistic and $p$ value from a repeatedmeasures ANOVA. * indicates $p<0.05$ versus baseline, paired sample t-test. These $p$ values are marked if they are significant after multiplicity correction. Paired t-test was used to compare month 6 values with baseline (without multiplicity correction) as the change at 6 months versus baseline was a prespecified endpoint. P values were calculated by using log-transformed ferritin, iron, hepcidin and hs-CRP levels. ANOVA, analysis of variance; hs-CRP, high-sensitive C reactive protein.

iron levels tended to decrease after leptin in our study population, these changes were not statistically significant in our relatively small sample size. However, leptin therapy was associated with reductions in triglycerides and hepatic fat along with significant decreases in ferritin and hs-CRP levels.

In conclusion, our data add to the growing body of evidence that iron metabolism may be more directly linked to the pathophysiology of insulin resistance than previously thought and support the notion that increasing leptin signal via exogenous administration may lower ferritin levels in a rare human metabolic disease associated with insulin resistance and diabetes. However, whether the decrease in ferritin directly indicates a decrease in iron stores or is mediated by an effect on inflammation remains not clear at this time.

Acknowledgements We are indebted to the participants for volunteering in the original partial lipodystrophy study.
Contributors EYA and SB performed data analyses and created the figure. EYA wrote the first draft of the manuscript. BJR and JFH performed measurements of the iron parameters. EAO designed the study, and provided oversight in the execution of the study, data analyses, and manuscript writing. She also followed the participants clinically and performed all regulatory reporting and correspondence. All other authors (PS, BA, AHN, and RH) contributed to data collection and analysis. All authors read and approved the final version of the letter. EAO is the guarantor of this work and, as such, had full access to all the data in the study and takes responsibility for the integrity of the data and the accuracy of the data analysis.

Funding The partial lipodystrophy study is supported by the National Institutes of Health (NIH) grant R01 DK088114. BJR was supported by NIH grant T32-DK007245 and F32-DK-117522.

Competing interests EAO reports the following conflicts: grant support: Aegerion Pharmaceuticals (now Amryt Pharmaceuticals), Ionis Pharmaceuticals, Akcea Therapeutics, Gemphire Therapeutics, Gl Dynamics (current), AstraZeneca (past 2 years); consultant or advisor: AstraZeneca, Thera Therapeutics, and BMS (past), Aegerion Pharmaceuticals (now Amryt Pharmaceuticals), Regeneron Pharmaceuticals (current); drug support: Aegerion Pharmaceuticals (now Amryt Pharmaceuticals), Akcea Therapeutics, Rhythm Pharmaceuticals (all current); other support: Aegerion Pharmaceuticals (now Amryt Pharmaceuticals), Regeneron Pharmaceuticals (current). BA has attended Scientific Advisory Board Meetings 
organized by Aegerion Pharmaceuticals (now Amryt Pharmaceuticals) and Regeneron Pharmaceuticals and has received honoraria as a speaker from AstraZeneca, Lilly, MSD, Novartis, Novo Nordisk, Boehringer-Ingelheim, Servier, and Sanofi-Aventis. Other authors report no conflicts of interest.

Patient consent for publication Not required.

Ethics approval The study was approved by the University of Michigan Institutional Review Board (IRBMED: HUM00058708). All participants gave informed consent before taking part.

Provenance and peer review Not commissioned; externally peer reviewed.

Open access This is an open access article distributed in accordance with the Creative Commons Attribution Non Commercial (CC BY-NC 4.0) license, which permits others to distribute, remix, adapt, build upon this work non-commercially, and license their derivative works on different terms, provided the original work is properly cited, appropriate credit is given, any changes made indicated, and the use is non-commercial. See: http://creativecommons.org/licenses/by-nc/4.0/.
ORCID iD

Elif A Oral http://orcid.org/0000-0002-9171-1144

\section{REFERENCES}

1 Gao Y, Li Z, Gabrielsen JS, et al. Adipocyte iron regulates leptin and food intake. J Clin Invest 2015;125:3681-91.

2 Andrews NC. Hungry irony. J Clin Invest 2015;125:3422-3.

3 Ford ES, Cogswell ME. Diabetes and serum ferritin concentration among U.S. adults. Diabetes Care 1999;22:1978-83.

4 Gillum RF. Association of serum ferritin and indices of body fat distribution and obesity in Mexican American men--the Third National Health and Nutrition Examination Survey. Int $\mathrm{J}$ Obes Relat Metab Disord 2001;25:639-45.

5 Facchini FS. Effect of phlebotomy on plasma glucose and insulin concentrations. Diabetes Care 1998:21:2190. 